\title{
High Flow Nasal Cannula Oxygen in Patients With Haematological Malignancy: A Retrospective Observational Study
}

Simon Tetlow ( $\nabla$ simon.tetlow@nhs.net)

University College Hospital https://orcid.org/0000-0002-3110-1125

Rathai Anandanadesan

Royal Brompton and Harefield NHS Foundation Trust

Leila Taheri

Guy's and St Thomas' NHS Foundation Trust

Eirini Pagkalidou

Aristotle University of Thessaloniki Department of Medicine: Aristoteleio Panepistemio Thessalonikes Tmema latrikes

Hugues De Lavallade

King's College Hospital NHS Foundation Trust

Victoria Metaxa

King's College Hospital NHS Foundation Trust

\section{Research}

Keywords: Haematology, cancer, non-invasive respiratory support, respiratory failure, supportive care.

Posted Date: March 18th, 2021

DOI: https://doi.org/10.21203/rs.3.rs-317897/v1

License: (c) (1) This work is licensed under a Creative Commons Attribution 4.0 International License. Read Full License

Version of Record: A version of this preprint was published at Annals of Hematology on April 8th, 2022. See the published version at https://doi.org/10.1007/s00277-022-04824-9. 


\section{Abstract}

Background

Patients with haematological malignancies (HM) face high rates of Intensive Care Unit (ICU) admission and mortality. High flow nasal cannula oxygen (HFNCO) is increasingly used to support HM patients in ward settings, but there is limited evidence on the safety and efficacy of HFNCO in this group.

\section{Methods}

We retrospectively reviewed all HM patients receiving ward-based HFNCO, supervised by a critical care outreach service (CCOS), from January 2014 - January 2019.

Results

We included 130 consecutive patients. Forty-three (33.1\%) were weaned off HFNCO without ICU admission. Eighty-seven (66.9\%) were admitted to ICU, 20 (23.3\%) required non-invasive and $34(39.5 \%)$ invasive mechanical ventilation. ICU and hospital mortality were $42 \%$ and $55 \%$ respectively. Initial FiO $2<0.4(\mathrm{OR}$ $0.27,95 \% \mathrm{Cl} 0.09-0.81, \mathrm{p}=0.019)$ and HFNCO use on the ward $>1$ day (OR 0.16, 95\% $\mathrm{Cl} 0.04,0.59, \mathrm{p}=0.006)$ were associated with reduced likelihood for ICU admission. Invasive ventilation was associated with reduced survival $(\mathrm{OR} 0.27,95 \% \mathrm{Cl} 0.1-0.7, \mathrm{p}=0.007)$. No significant adverse events were reported.

Conclusion

HM patients receiving ward-based HFNCO have higher rates of ICU admission, but comparable hospital mortality to those requiring CCOS review without respiratory support. Results should be interpreted cautiously, as the model proposed depends on the existence of CCOS.

\section{Introduction}

Patients with haematological malignancies (HM) undergo complex treatment regimens that are associated with prolonged phases of neutropenia, sepsis, graft-versus-host disease (GvHD) and other chemotherapy related toxicities. ${ }^{1}$ Despite advances in treatments, Intensive Care Unit (ICU) admission rates for these patients still range from 9-20\%, with reported ICU mortality being around $40-50 \%{ }^{2,3}$ Outcomes remain worse for those who require mechanical ventilation and multiple organ support. ${ }^{4}$ Avoiding intubation and invasive mechanical ventilation (IMV) have been the focus of recent research, ${ }^{5-7}$ as it has been linked to a decreased risk of death. 8,9 The use of non-invasive ventilation (NIV) has returned conflicting results, ${ }^{6,7,10}$ raising concerns around delays in treatment escalation ${ }^{11}$ and patient comfort. ${ }^{12}$

High flow nasal cannula oxygen (HFNCO) therapy is a novel mode of oxygen delivery, the advantages of which have attracted attention in recent years. HFNCO is able to deliver heated and humidified gas with a fraction of inspired oxygen concentration $\left(\mathrm{FiO}_{2}\right)$ of 0.21 to 1.0 and flows of up to $60 \mathrm{~L} / \mathrm{min}$. The high flow rates generated by HFNCO can satisfy the patient's inspiratory flow requirements, reduce dead space ventilation and rebreathing, and improve atelectasis by generating a degree of positive end-expiratory pressure (PEEP). ${ }^{13,14}$ As a result, HFNCO has had an increasing role in treating Type I (hypoxaemic) acute respiratory failure (ARF), with data demonstrating reduced need for escalation of respiratory support, reduced work of breathing and increased patient comfort. ${ }^{15,16}$ Confusingly, other studies have yielded conflicting results, finding no improvement in intubation rates. ${ }^{5,17}$ Despite the absence of conclusive data and general recommendations, the use of HFNCO appears to be changing the management of patient with ARF.

The same conflicting results are evident in the studies that assess the effect of HFNCO in the outcomes of immunocompromised patients, with one review reporting a reduction in short-term mortality and intubation rates and another finding no difference in ICU and 28 -day mortality. ${ }^{18,}{ }^{19}$ Furthermore, the majority of studies include patients with HM already admitted to ICU, ${ }^{5}$ whereas those evaluating HFNCO for hypoxaemic ARF outside ICU were undertaken in the general population, rather than patients with $\mathrm{HM}^{20,21}$

The aim of this retrospective study was to describe the use of HFNCO, supported by a Critical Care Outreach Service (CCOS), in patients with HM on the ward and to determine its efficacy, safety and tolerability.

\section{Methodology}

All patients with HM reviewed by the CCOS between January 2014 and January 2019 at our tertiary haemato-oncology institution were included in this retrospective study.

The hospital runs a CCOS as a seven-day, 24-h service, comprised of a team of two ICU-trained nurses, a senior ICU trainee and a dedicated consultant. The work of the team has been described previously 22 (see appendix). In summary, the decision to initiate and the management of HFNCO is controlled by the CCOS. The therapy is delivered by the Fisher \& Paykel Optiflow system, using the MR850 respiratory humidifier with MR290 chamber; RT241 heated delivery tubing, and RT033 or RT044 small or wide bore nasal cannulae (Fisher \& Paykel Healthcare, Auckland, New Zealand). If the CCOS believes that non-escalation of treatment is appropriate, then consideration of end-of-life (EoL) is suggested to the parent team.

All patients > 18 years/old, diagnosed with a HM and who received HFNCO on the ward were included. Patients were defined as having a haematopoietic stem cell transplant (HSCT) if they received a stem cell infusion during their hospital admission. Patients who underwent conditioning but did not receive stem cell support were defined as not having had a HSCT. Data was extracted retrospectively from paper and electronic health records, using a standardized data collection tool. 
The study was endorsed by the Trust's Service Evaluation Committee as a Quality Improvement Project (ref.

number KCC31032019TUO) and Research Ethics Committee approval was not deemed necessary. This project did not receive any specific grant from funding agencies in the public, commercial, or not-for-profit sectors.

\section{Statistical Analysis}

The baseline characteristics of the patients who participated in the study were calculated. The Mann-Whitney U test was used to compare differences when the independent variable was continuous, whereas chi-square test was used for comparisons between categorical variables. Logistic regression was performed to examine which variables influenced ICU admission and hospital mortality using the backward elimination method. The variables were included in the multivariate analysis when a p value $<0.2$ was observed in the univariate analysis. In the logistic regression model, the categories of independent variables with very low or no patient frequency joined the higher frequency categories, in order to assess the model. Survival analysis was applied between the patients who received HFNCO in ICU versus outside of ICU. Relationships with a p value of lees than 0.05 were considered as statistically significant.

\section{Results}

Between January 2014 and January 2019, 130 consecutive HM patients received HFNCO in a ward setting under the supervision of the CCOS (Table 1). Over the same period, the CCOS reviewed 830 patients with a HM. Haematopoetic stem Cell Transplantation-Specific Comorbidity Index (HCTCl) Scores were available for 65 patients, of whom $30(46.2 \%)$ had an $\mathrm{HCTCl}$ score of 3 or greater indicating a high risk of relapse-free mortality. ${ }^{23}$

Table 1

Demographic and haematological characteristics

\section{Characteristics}

Gender

Female

Age at admission

$>60$

Haematological Diagnoses

Myeloid

Lymphoid

Other

HSCT on this admission

No

Yes

Type of HSCT

Allogeneic

Autologous

Disease status at admission

Remission

New diagnosis

Palliative

Active disease

NA

Comorbidities

Respiratory disease

Cardiovascular disease

Renal disease

Other comorbidities

HSCT: haematopoietic stem cell transplant; NA: non-available. Lymphoid includes lymphoma, myeloma, and lymphocytic leukaemia. Myeloid includes myelodysplastic syndrome, myeloproliferative syndrome, and myelogenous leukaemia. $n(\%)$

$40(30.8)$

$64(49.2)$

$80(61.5)$

39 (30.0)

$11(8.5)$

86 (66.2)

44 (33.8)

$39(30.0)$

5 (3.8)

58 (44.6)

17 (13.1)

4 (3.1)

43 (33.1)

8 (6.2)

$39(30.0)$

$26(20)$

10 (7.7)

$82(63.1)$

\section{Initiation of HFNCO}


Table 2 describes the reasons for referral to the CCOS and the indications for HFNCO initiation. Seventy-six patients (58.5\%) had a respiratory rate of $\geq 25$ breaths/min, and $73(56.2 \%)$ had a heart rate $\geq 100$ beats/min documented before initiation of the treatment. The most common cause for ARF was infection (97 patients, $74.6 \%$ ) and HFNCO was initiated early in the course of the disease, as $116(89.2 \%)$ patients had $\mathrm{SpO}_{2}>90 \%$ and $62.3 \% \mathrm{SpO}_{2}>94 \%$, before initiation of HFNCO. The initial device settings were flow of $\geq 60 \mathrm{~L} / \mathrm{min}$ for 71 (54.6\%) and $\mathrm{FiO}_{2} \geq 0.4$ for 91 (70\%) patients.

Table 2

Reasons for CCOS referral and HFNCO initiation

\begin{tabular}{|l|l|}
\hline Reason for CCOS referral & $\mathbf{n}(\%)$ \\
\hline High NEWS score & $31(23.8)$ \\
\hline Respiratory failure & $75(57.7)$ \\
\hline ICU step down/reviews & $2(1.5)$ \\
\hline General concern & $5(3.8)$ \\
\hline Hypotension & $10(7.7)$ \\
\hline Other & 7 (5.4) \\
\hline Indication for HFNCO & $\mathbf{n ( \% )}$ \\
\hline Type I RF & $60(46.2)$ \\
\hline WOB/dyspnoea & $65(50.0)$ \\
\hline Palliative care/symptom control & $4(3.1)$ \\
\hline Not documented & $1(0.8)$ \\
\hline $\begin{array}{l}\text { CCOS: critical care outreach service; HFNCO: high flow nasal cannula oxygen. Respiratory failure includes increased work of breathing (WOB), hypoxia } \\
\text { (SpO } 2 \text { 94\%) or a subjective feeling of shortness of breath (SOB); type ! RF: type I respiratory failure }\end{array}$ & \\
\hline
\end{tabular}

\section{Outcome of patients without ICU admission}

Forty-three patients (33\%) who received HFNCO didn't require ICU escalation and remained on the ward. For 5 of these patients (11.6\%), HFNCO was administered for less than one day, whilst 26 patients (60.5\%) received the treatment for 1 to 3 days and 12 (27.9\%) for more than 3 days. Amongst the patients never admitted to ICU, hospital survival was $53.5 \%$ (HR 0.99, 95\% $\mathrm{Cl} 0.41-2.38, \mathrm{p}=0.976$ ), whereas 90 -day and 1 -year survival were $46.5 \%$ and $23.3 \%$ respectively. No significant adverse events were associated with the use of HFNCO (Table 3 ).

Table 3 Adverse effects of HFNCO

\begin{tabular}{|ll|}
\hline Adverse event & $\mathbf{n}(\%)$ \\
\hline None & $105(80.8)$ \\
\hline Unable to tolerate the therapy & $12(9.2)$ \\
\hline Sensation of excessive heat & $8(6.2)$ \\
\hline Epistaxis & $4(3.1)$ \\
\hline Excessive noise from the device & $1(0.8 \%)$ \\
\hline HFNCO: high flow nasal cannula oxygen. \\
\hline
\end{tabular}

\section{Outcome of patients requiring ICU admission}

Seventy patients (53.8\%) had to be admitted to ICU within 24 hours of starting HFNCO and further $17(13.1 \%)$ after a median of 4 days (IQR = 2). In comparison, during the same timeframe, CCOS reviewed a total of 830 patients with HM. Of those, 316 (38\%) where admitted to ICU. Of the 87 patients $(66.9 \%)$ that needed ICU admission, 20 (23.3\%) required escalation of respiratory support to NIV and 34 (39.5\%) necessitated intubation and ventilation in ICU. The rest of the patients $(33,37.9 \%)$ were admitted to ICU for organ support other than respiratory (predominantly need for vasopressors).

Of the 87 patients admitted to ICU after a trial of HFNCO on the ward, $50(57.5 \%)$ survived to ICU discharge. Thirty-six of the ICU patients (41.8\%) survived to hospital discharge, whereas 38 (43.7\%) and 18 (20.7\%) were alive after 90 days and 1 year, respectively. Eight patients required re-admission to ICU outside the study period and of those, 2 (25\%) didn't survive the second ICU admission and 3 (37.5\%) died before leaving the hospital.

\section{Predictors of ICU admission}

Undergoing HSCT during their hospital stay, the type of HSCT, patient's age, the reason for deterioration on the ward, the initial device settings and the duration of HFNCO use on the ward were identified as statistically significant predictors for ICU admission in the univariate model. In the multivariate analysis, only an initial $\mathrm{FiO}_{2}$ of $<0.4(\mathrm{OR} 0.27,95 \% \mathrm{Cl} 0.09-0.81, \mathrm{p}=0.019)$ and the duration of HFNCO use on the ward were associated with reduced likelihood for ICU admission. The probability to be admitted to ICU was reduced the more days the patients spent on HFNCO on the ward $(\mathrm{OR} 0.16,95 \% \mathrm{Cl} 0.04-0.59, \mathrm{p}=0.006$ 
for $1-3$ days vs. OR $0.06,95 \% \mathrm{Cl} 0.01-0.38,0=0.002$ ) (Table 4 ). No statistically significant association was found between the number of days receiving HFNCO on the ward and intubation or ICU mortality (Supplementary table 1).

Table 4

Analysis of factors associated with ICU admission

\begin{tabular}{|c|c|c|c|c|c|c|}
\hline \multirow[b]{2}{*}{ Variables } & \multicolumn{3}{|c|}{ Univariate Analysis } & \multicolumn{3}{|c|}{ Multivariable Analysis } \\
\hline & OR & $95 \% \mathrm{Cl}$ & p-value & OR & $95 \% \mathrm{Cl}$ & p-value \\
\hline \multicolumn{7}{|l|}{ Age (years) } \\
\hline$>60 / \leq 60$ & 0.48 & $0.23,0.99$ & 0.050 & 0.89 & $0.32,2.43$ & 0.816 \\
\hline \multicolumn{7}{|l|}{ HSCT } \\
\hline Yes/No & 3.24 & $1.35,7.79$ & 0.009 & 3.15 & $0.80,12.37$ & 0.101 \\
\hline \multicolumn{7}{|l|}{ Allogeneic transplant } \\
\hline Autologous & 0.74 & $0.16,3.30$ & 0.690 & 0.43 & $0.07,2.71$ & 0.372 \\
\hline NA & 0.45 & $0.20,0.99$ & 0.049 & 0.56 & $0.15,2.06$ & 0.384 \\
\hline Allogeneic (ref) & 1 & 1 & 1 & 1 & 1 & 1 \\
\hline \multicolumn{7}{|l|}{ Aetiology of deterioration } \\
\hline Fluid overload/pulmonary oedema & 0.56 & $0.16,1.99$ & 0.365 & 0.72 & $0.15,3.38$ & 0.679 \\
\hline GvHD lung & 0.93 & $0.08,10.72$ & 0.954 & 0.24 & $0.01,4.52$ & 0.340 \\
\hline Other & 3.26 & $0.69,15.36$ & 0.135 & 2.84 & $0.53,15.20$ & 0.222 \\
\hline Sepsis (ref) & 1 & 1 & 1 & 1 & 1 & 1 \\
\hline$<0.4 \% / \geq 0.4 \%$ & 0.49 & $0.21,1.17$ & 0.107 & 0.27 & $0.09,0.81$ & 0.019 \\
\hline \multicolumn{7}{|l|}{ HR at HFNCO initiation } \\
\hline$<100 / \min / \geq 100$ & 0.55 & $0.25,1.22$ & 0.143 & 0.44 & $0.16,1.21$ & 0.110 \\
\hline \multicolumn{7}{|l|}{ Days spent on HFNCO on ward } \\
\hline $1-3$ & 0.19 & $0.06,0.61$ & 0.005 & 0.16 & $0.04,0.59$ & 0.006 \\
\hline$>3$ & 0.18 & $0.05,0.69$ & 0.012 & 0.06 & $0.01,0.38$ & 0.002 \\
\hline 1 (ref) & 1 & 1 & 1 & 1 & 1 & 1 \\
\hline
\end{tabular}

\section{Predictors of ICU and hospital mortality}

On univariate analysis, receiving IMV and having a history of HSCT was found to be associated with reduced chance of survival to ICU and hospital discharge (OR $0.19,95 \% \mathrm{Cl} 0.08-0.44, \mathrm{p}=<0.001$ and $\mathrm{OR} 0.35,95 \% \mathrm{Cl} 0.16-0.77, \mathrm{p}=<0.009$ respectively). Only intubation and IMV were found to be significantly associated with reduced ICU and hospital survival in the multivariate analysis $(\mathrm{OR} 0.03,95 \% \mathrm{Cl} 0.002-0.31, \mathrm{p}=0.004$ and $\mathrm{OR} 0.27,95 \% \mathrm{Cl} 0.1-0.7, \mathrm{p}=0.007$, respectively) (Supplementary tables 2 and 3).

Regarding therapy-related factors, only the indication for treatment showed statistically significant association with ICU survival (Table 5). More specifically, patients that were started on HFNCO for type I ARF were 2.48 times more likely to survive to ICU discharge than those who received HFNCO for increased workof-breathing and/or dyspnoea (OR $2.48,95 \% \mathrm{Cl} 1.08-5.73, \mathrm{p}=0.033$ ). Having a heart rate of < 100beats/min on initiation of HFNCO approached but did not reach statistical significance $(p=0.065)$ in the multivariate analysis for ICU survival. 
Table 5

Therapy - related factors associated with ICU survival

\begin{tabular}{|c|c|c|c|c|c|c|}
\hline \multirow[b]{2}{*}{ Variable } & \multicolumn{3}{|c|}{ Univariate Analysis } & \multicolumn{3}{|c|}{ Multivariable Analysis } \\
\hline & OR & $95 \% \mathrm{Cl}$ & p-value & OR & $95 \% \mathrm{Cl}$ & p-value \\
\hline \multicolumn{7}{|l|}{ Overall response to HFNCO } \\
\hline Escalated of respiratory support required & 0.20 & $0.04,1.12$ & 0.067 & 0.94 & $0.22,4.00$ & 0.939 \\
\hline Admission to ICU & 1.28 & $0.34,4.76$ & 0.706 & 1.61 & $0.41,6.25$ & 0.494 \\
\hline Improved and weaned & 1 & 1 & 1 & 1 & 1 & 1 \\
\hline \multicolumn{7}{|l|}{ Indication for HFNCO } \\
\hline T1RF/WOB-SOB & 1.85 & $0.84,4.09$ & 0.129 & 2.48 & $1.08,5.73$ & 0.033 \\
\hline \multicolumn{7}{|l|}{ Parameters at HFNCO initiation: RR } \\
\hline$\geq 25 /<25 / \mathrm{min}$ & 0.56 & $0.24,1.29$ & 0.171 & 1.88 & $0.77,4.58$ & 0.164 \\
\hline \multicolumn{7}{|l|}{ Parameters at HFNCO initiation: HR } \\
\hline$\geq 100 /<100 / \mathrm{min}$ & 0.57 & $0.25,1.30$ & 0.181 & 0.45 & $0.19,1.05$ & 0.065 \\
\hline
\end{tabular}

\section{Treatment Escalation Planning}

The CCOS frequently assisted the haematology team in treatment escalation planning. On admission, 119 (91.5\%) of patients were for full escalation of treatment including cardiopulmonary resuscitation (CPR). Following CCOS referral and review of patients, there was a change in the treatment escalation plan (TEP) by the parent team, with 42 (32.3\%) patients being recognised as EoL. Of those, $32(76.2 \%)$ remained of HFNCO for more than one day after the TEP decision and 9 (21.4\%) for more than 3 days. Seven of the $42(16.7 \%)$ patients identified as EoL, survived to hospital discharge.

\section{Discussion}

By exploring a single centre's experience of providing HFNCO to a population of ward-based haemato-oncology patients, we provide the first description of the treatment's efficacy and safety in this setting. Approximately $67 \%$ of patients receiving HFNCO were admitted to ICU and of those, $40 \%$ required intubation and IMV. Device settings at initiation and duration of stay on the ward were predictors of ICU admission. Patients' ICU and hospital mortality were $42 \%$ and $55 \%$ respectively and were associated with the underlying reason for initiating HFNCO. In approximately $22 \%$ of patients that were recognized as EoL, treatment was continued for more than 3 days. This is, to our knowledge, the first report in patients with HM receiving HFNCO outside of ICU.

We report that more than $60 \%$ of the patients who received HFNCO on the ward were subsequently admitted to ICU, a percentage that is higher than the average admission rate for HM patients requiring CCOS review in our institution (38\%), probably because they represent a sicker sub-population.

Over the last decade, there has been a gradual increase in the proportion of HM patients that get admitted to ICU (7 to $75 \%)$. $3424-26$ A possible explanation for this is the shifting mentality in the critical care community away from the nihilistic perception that precluded consideration of these patients for advanced support. ${ }^{27}$ When considering predictors of admission to critical care, previous publications have highlighted patient-related factors, such as the presence of $\mathrm{GvHD}^{25}$ In the present study, we identified a therapy-related factor, an initial $\mathrm{FiO}_{2}$ lower than 0.4 , to be associated with decreased ICU admission. The lower $\mathrm{FiO}_{2}$ suggests that the patients who improved without going to ICU, probably had less severe ARF than those who needed admission. Unfortunately, the retrospective nature of the study meant that an accurate calculation of the $\mathrm{pO}_{2} / \mathrm{FiO}_{2}$ or the respiratory rate-oxygenation ( $\mathrm{ROX}$ ) index ${ }^{28}$ was not possible. Nonetheless, the reported HFNCO failure rate in the present study (indicated by the need for ICU admission and escalation of respiratory support) was approximately $42 \%$, which is consistent with other results. ${ }^{17,29}$

One of the most challenging decisions in the management of patients with ARF is the decision to escalate respiratory support. Studies have shown that delayed intubation and IMV in patients receiving HFNCO is associated with increased ICU mortality. ${ }^{30}$ This issue becomes even more pertinent in the immunocompromised population, where delays in escalation can have even more detrimental effects. ${ }^{11}$ In the present study, the days that the patients received HFNCO on the ward had no impact on mortality, a finding that was also observed in a previous publication from the same institution. ${ }^{22}$ On the contrary, our results suggest that patients who stayed on the ward for more than 24 hours were less frequently admitted to ICU. This result needs to be interpreted with caution, as the design of the study precludes robust conclusions from being drawn regarding the role of HFNCO in averting ICU admissions. A possible explanation is that patients who didn't deteriorate rapidly (within 24 hours) on HFNCO, were less critically ill, required less intensive organ support and had better survival. This is in accordance with previous publications highlighting the absence of improvement as an important factor of treatment failure and worse outcomes, both for HFNCO ${ }^{30}$ and $\mathrm{NIV}^{31,32}$

In recent years, both the ICU and hospital survival of patients with HM have improved significantly, as a result of combined technological and therapeutic advances in both medical fields. ${ }^{3,4}$ Our reported mortality in ICU (42\%) and hospital (55\%) are comparable to those mentioned elsewhere, ${ }^{4,33,34}$ as are the worse outcomes that follow IMV in this patient population. An interesting finding was that when HFNCO was initiated for hypoxia, ICU survival was 2.5 times more likely than when the indication was 'softer', i.e., for increased work of breathing or dyspnoea. This result can be explained by the fact that approximately 
$75 \%$ of the ARF was due to infection, even if the study wasn't designed to specifically distinguish between infective aetiologies. A large, multicentre study has identified an undetermined cause of ARF as an independent factor for mortality, ${ }^{35}$ a finding that is repeatedly observed in the relevant literature. ${ }^{36}$ The poorer outcomes associated with an undetermined reason for ARF could be a result of delay that ensues from the failure to recognise and treat a pulmonary complication.

The use of HFNCO in immunocompromised patients was summarised in two recent systematic reviews, which both concluded that the treatment reduced the need for intubation but yielded conflicting results regarding the effect on mortality. ${ }^{18,19}$ Both those reviews only included patients that received HFNCO in ICU, which leaves the question about the efficacy of the therapy delivered on the ward, unanswered. This question becomes pertinent in countries with low ICU bed availability, such as the UK which has fewer (6.6) beds per 100,000 capita of population than other European countries. ${ }^{37}$ The introduction of CCOS aims, among other things, to avert inappropriate and ensure timely admissions to ICU, when required. ${ }^{38}$ Their positive impact on patients with HM has been highlighted in a few studies, without the focus ever being on the use of HFNCO. ${ }^{22,24,26}$ The present study, supports the results of another, smaller one from the same institution ${ }^{22}$ and crystalises the need for trials that assess the efficacy of HFNCO in immunocompromised patients outside of ICU. In the meantime, it provided reassurance towards the safety of the intervention, as hospital, 90-day and 1-year survival was comparable between those patients that were admitted to ICU and those that remained on the ward.

The role of CCOS in EoL decision-making has been previously described previously in the HM population. ${ }^{22,39}$ However, the role of HFNCO in the last days of a patient's life remains unknown, with concerns being raised around potential prolongation of the dying process without any meaningful benefit. ${ }^{40,41}$ Our findings show that approximately $20 \%$ of the patients that were recognised as EoL after review from CCOS, remained on HFNCO for more than 3 days after the TEP was set. As this study wasn't designed to investigate the effect of HFNCO around EoL, it is difficult to ascertain the impact of this therapy on the dying process. However, the fact that no adverse events were reported suggests that the use of HFNCO doesn't add significant discomfort around EoL and could potentially be used in this patient population as well. Interestingly, $17 \%$ of the patients that were identified as dying while receiving the treatment survived to hospital discharge.

The main limitations of the study are its retrospective nature, which precludes any inferred causality and the lack of control group, that would have allowed for direct comparisons. Despite this, our results are concordant with the published literature, which increases their validity and allows for strong associations to be drawn. Another limitation is that the observational nature of the study meant that the initiation of HFNCO and its escalation to other modes of respiratory support were dependent on the individual physician, as no protocol for administration of HFNCO exists in our institution. This is an inherent issue with retrospective, observational studies and only properly conducted randomised trials will adjust for potential confounders. Last, the use of HFNCO on the ward and the existence of an outreach team may not be commonplace in countries outside the UK. Nonetheless, the results of an Australian study has reported similar use of HFNCO outside the ICU, ${ }^{42}$ with support from an outreach service, increasing awareness about its safe use in this setting.

\section{Conclusion}

One third of the haemato-oncology patients who received HFNCO on the ward didn't require ICU escalation and were successfully weaned off. Hospital, 90 -day and 1-year survival for these patients was comparable to their ICU counterparts. Patients that didn't deteriorate within the first 24 hours after initiation were less frequently admitted to ICU. No significant adverse events were documented and no negative association was reported regarding to the duration of the therapy on the ward. An important part of the CCOS role is participation in establishing new TEPs and using HFNCO around EoL, for a notable proportion of patients with HM. Caution is warranted as the model proposed here is dependent on the existence of an established CCOS, which is able to recognise early and promptly respond to clinical deteriorations.

\section{Abbreviations}

- ARF: Acute Respiratory Failure

- CPR: Cardiopulmonary Resuscitation

- CCOS: Critical Care Outreach Service

- EoL: End of Life

- FiO2: Fraction of Inspired Oxygen

- GvHD: Graft vs Host Disease

- HCTCl: Hematopoietic Cell Transplantation-Comorbidity Index

- HFNCO: High-Flow Nasal Cannula Oxygen

- HM: Haematological Malignancy

- HR: Hazard Ratio

- HSCT: Haematopoietic Stem Cell Transplant

- ICU: Intensive Care Unit

- IMV: Invasive Mechanical Ventilation

- NIV: Non-Invasive Ventilation

- PEEP: Positive End-Expiratory Pressure

- TEP: Treatment Escalation Plan 


\section{Declarations}

Ethics Approval: The study was endorsed by the King's College Hospital Service Evaluation Committee as a Quality Improvement Project (ref. number KCC31032019TUO) and Research Ethics Committee approval was not deemed necessary.

Consent for Publication: Not applicable.

Availability of Data and Materials: The datasets used and analysed during the current study are available from the corresponding author on reasonable request.

Competing Interests: The authors declare that they have no competing interests

Funding: This project did not receive any specific grant from funding agencies in the public, commercial, or not-for-profit sectors.

\section{Authors' Contributions:}

ST conceptualized the project along with VM, designed the data collection methodology, led the data collection, and was a major contributor in writing and editing the manuscript.

RA contributed to the data collection, curated the data, and was a major contributor in writing and editing the manuscript.

LT contributed to the data collection, curated the data, and contributed to writing and editing the manuscript.

EP performed statistical analysis on the data.

H De L assisted in conceptualizing the project, and contributed towards writing and editing the manuscript.

VM conceptualized the project along with ST, supervised the project and was a major contributor in writing and editing the manuscript

All authors have read and approved the final manuscript.

Acknowledgements: Not applicable

\section{References}

1. Mohty B, Mohty M. Long-term complications and side effects after allogeneic hematopoietic stem cell transplantation: an update. Blood Cancer Journal. 2011;1(4):e16-6.

2. Bayraktar U, Nates J. Intensive care outcomes in adult hematopoietic stem cell transplantation patients. World Journal of Clinical Oncology. $2016 ; 7(1): 98$.

3. Azoulay E, Mokart D, Pène F, Lambert J, Kouatchet A, Mayaux J, et al. Outcomes of Critically III Patients With Hematologic Malignancies: Prospective Multicenter Data From France and Belgium-A Groupe de Recherche Respiratoire en Réanimation Onco-Hématologique Study. J Clin Oncol. 2013;31(22):2810-8.

4. Grgić Medić M, Gornik I, Gašparović V. Hematologic malignancies in the medical intensive care unit - Outcomes and prognostic factors. Hematology. 2014;20(5):247-53.

5. Lemiale V, Mokart D, Mayaux J, Lambert J, Rabbat A, Demoule A, et al. The effects of a 2-h trial of high-flow oxygen by nasal cannula versus Venturi mask in immunocompromised patients with hypoxemic acute respiratory failure: a multicenter randomized trial. Critical Care. 2015;19(1).

6. Azoulay E, Lemiale V. Non-invasive mechanical ventilation in hematology patients with hypoxemic acute respiratory failure: a false belief? Bone Marrow Transplant. 2012;47(4):469-72.

7. Gristina G, Antonelli M, Conti G, Ciarlone A, Rogante S, Rossi C, et al. Noninvasive versus invasive ventilation for acute respiratory failure in patients with hematologic malignancies: A 5-year multicenter observational survey*. Crit Care Med. 2011;39(10):2232-9.

8. Azevedo L, Caruso P, Silva U, Torelly A, Silva E, Rezende E, et al. Outcomes for Patients With Cancer Admitted to the ICU Requiring Ventilatory Support. Chest. 2014;146(2):257-66.

9. Azoulay E, Lemiale V, Mokart D, Pène F, Kouatchet A, Perez P, et al. Acute respiratory distress syndrome in patients with malignancies. Intensive Care Med. 2014;40(8):1106-14.

10. Hilbert G, Gruson D, Vargas F, Valentino R, Gbikpi-Benissan G, Dupon M, et al. Noninvasive Ventilation in Immunosuppressed Patients with Pulmonary Infiltrates, Fever, and Acute Respiratory Failure. N Engl J Med. 2001;344(7):481-7.

11. Mokart D, Lambert J, Schnell D, Fouché L, Rabbat A, Kouatchet A, et al. Delayed intensive care unit admission is associated with increased mortality in patients with cancer with acute respiratory failure. Leuk Lymphoma. 2012;54(8):1724-9.

12. Azoulay É, Kouatchet A, Jaber S, Lambert J, Meziani F, Schmidt M, et al. Noninvasive mechanical ventilation in patients having declined tracheal intubation. Intensive Care Med. 2012;39(2):292-301.

13. Hernández G, Roca O, Colinas L. High-flow nasal cannula support therapy: new insights and improving performance. Critical Care. 2017;21(1).

14. Ischaki E, Pantazopoulos I, Zakynthinos S. Nasal high flow therapy: a novel treatment rather than a more expensive oxygen device. European Respiratory Review. 2017;26(145):170028. 
15. Zhao H, Wang H, Sun F, Lyu S, An Y. High-flow nasal cannula oxygen therapy is superior to conventional oxygen therapy but not to noninvasive mechanical ventilation on intubation rate: a systematic review and meta-analysis. Critical Care. 2017;21(1).

16. Lee C, Mankodi D, Shaharyar S, Ravindranathan S, Danckers M, Herscovici P, et al. High flow nasal cannula versus conventional oxygen therapy and noninvasive ventilation in adults with acute hypoxemic respiratory failure: A systematic review. Respiratory Medicine. 2016;121:100-8.

17. Frat J, Thille A, Mercat A, Girault C, Ragot S, Perbet S, et al. High-Flow Oxygen through Nasal Cannula in Acute Hypoxemic Respiratory Failure. N Engl J Med. 2015;372(23):2185-96.

18. Cortegiani A, Crimi C, Sanfilippo F, Noto A, Di Falco D, Grasselli G, et al. High flow nasal therapy in immunocompromised patients with acute respiratory failure: A systematic review and meta-analysis. J Crit Care. 2019;50:250-6.

19. Huang H, Peng J, Weng L, Liu G, Du B. High-flow oxygen therapy in immunocompromised patients with acute respiratory failure: A review and metaanalysis. J Crit Care. 2018;43:300-5.

20. Epstein A, Hartridge-Lambert S, Ramaker J, Voigt L, Portlock C. Humidified High-Flow Nasal Oxygen Utilization in Patients with Cancer at Memorial SloanKettering Cancer Center. Journal of Palliative Medicine. 2011;14(7):835-9.

21. Rittayamai N, Tscheikuna J, Praphruetkit N, Kijpinyochai S. Use of High-Flow Nasal Cannula for Acute Dyspnea and Hypoxemia in the Emergency Department. Respir Care. 2015;60(10):1377-82.

22. Taheri L, Anandanadesan R, de Lavallade H, Pagkalidou E, Pagliuca A, Mufti G, et al. The role of a critical care outreach service in the management of patients with haematological malignancy. Journal of the Intensive Care Society. 2019;20(4):327-34.

23. Charlson M, Pompei P, Ales K, MacKenzie C. A new method of classifying prognostic comorbidity in longitudinal studies: Development and validation. Journal of Chronic Diseases. 1987;40(5):373-83.

24. Hayani O, Al-Beihany A, Zarychanski R, Chou A, Kharaba A, Baxter A, et al. Impact of critical care outreach on hematopoietic stem cell transplant recipients: a cohort study. Bone Marrow Transplant. 2011;46(8):1138-44.

25. Benz R, Schanz U, Maggiorini M, Seebach J, Stussi G. Risk factors for ICU admission and ICU survival after allogeneic hematopoietic SCT. Bone Marrow Transplant. 2014;49(1):62-5.

26. Bokhari S, Munir T, Memon S, Byrne J, Russell N, Beed M. Impact of critical care reconfiguration and track-and-trigger outreach team intervention on outcomes of haematology patients requiring intensive care admission. Ann Hematol. 2010;89(5):505-12.

27. Azoulay E, Pène F, Darmon M, Lengliné E, Benoit D, Soares M, et al. Managing critically III hematology patients: Time to think differently. Blood Rev. 2015;29(6):359-67.

28. Roca O, Messika J, Caralt B, García-de-Acilu M, Sztrymf B, Ricard J, et al. Predicting success of high-flow nasal cannula in pneumonia patients with hypoxemic respiratory failure: The utility of the ROX index. J Crit Care. 2016;35:200-5.

29. Koga Y, Kaneda K, Mizuguchi I, Nakahara T, Miyauchi T, Fujita M, et al. Extent of pleural effusion on chest radiograph is associated with failure of highflow nasal cannula oxygen therapy. J Crit Care. 2016;32:165-9.

30. Kang B, Koh Y, Lim C, Huh J, Baek S, Han M, et al. Failure of high-flow nasal cannula therapy may delay intubation and increase mortality. Intensive Care Med. 2015;41(4):623-32.

31. Antonelli M, Conti G, Moro M, Esquinas A, Gonzalez-Diaz G, Confalonieri M, et al. Predictors of failure of noninvasive positive pressure ventilation in patients with acute hypoxemic respiratory failure: a multi-center study. Intensive Care Med. 2001;27(11):1718-28.

32. Moretti M, Cilione C, Tampieri A, Fracchia C, Marchioni A, Nava S. Incidence and causes of non-invasive mechanical ventilation failure after initial success. Thorax. 2000;55(10):819-25.

33. Hampshire P, Welch C, McCrossan L, Francis K, Harrison D. Admission factors associated with hospital mortality in patients with haematological malignancy admitted to UK adult, general critical care units: a secondary analysis of the ICNARC Case Mix Programme Database. Crit Care. 2009;13(4):R137.

34. Bird G, Farquhar-Smith P, Wigmore T, Potter M, Gruber P. Outcomes and prognostic factors in patients with haematological malignancy admitted to a specialist cancer intensive care unit: a 5 year study. Br J Anaesth. 2012;108(3):452-9.

35. Azoulay E, Pickkers P, Soares M, Perner A, Rello J, Bauer P, et al. Acute hypoxemic respiratory failure in immunocompromised patients: the Efraim multinational prospective cohort study. Intensive Care Med. 2017;43(12):1808-19.

36. Contejean A, Lemiale V, Resche-Rigon M, Mokart D, Pène F, Kouatchet A, et al. Increased mortality in hematological malignancy patients with acute respiratory failure from undetermined etiology: a Groupe de Recherche en Réanimation Respiratoire en Onco-Hématologie (Grrr-OH) study. Annals of Intensive Care. 2016;6(1).

37. Rhodes A, Ferdinande P, Flaatten H, Guidet B, Metnitz P, Moreno R. The variability of critical care bed numbers in Europe. Intensive Care Med. 2012;38(10):1647-53.

38. Department of Health T. Comprehensive critical care: a review of adult critical care services [Internet]. National Archives. 2000 [cited 10 March 2021]. Available from:

https://webarchive.nationalarchives.gov.uk/20121014090959/http://www.dh.gov.uk/prod_consum_dh/groups/dh_digitalassets/@dh/@en/documents/di

39. Pattison N, O'Gara G, Wigmore T. Negotiating, Transitions. Involvement of Critical Care Outreach Teams in End-of-Life Decision Making. Am J Crit Care. 2015;24(3):232-40.

40. Davies J. Noninvasive Respiratory Support at the End of Life. Respir Care. 2019;64(6):701-11.

41. Papazian L, Corley A, Hess D, Fraser J, Frat J, Guitton C, et al. Use of high-flow nasal cannula oxygenation in ICU adults: a narrative review. Intensive Care Med. 2016;42(9):1336-49. 
42. Pirret A, Takerei S, Matheson C, Kelly M, Strickland W, Harford J, et al. Nasal high flow oxygen therapy in the ward setting: A prospective observational study. Intensive Critical Care Nursing. 2017;42:127-34.

43. Additional Files.

44. File name: Additional File 1.

45. File format:.docx.

46. Title of Data: Results Tables.

47. Description of Data. Tables of numerical results data referenced in body of text.

48. File name: Additional File 2.

49. File format.docx.

50. Title of Data: Supplementary Data.

51. Description of Data. Supplementary data. This describes the critical care outreach service at the study centre, and the National Early Warning Scoring system which contributes to referral to the critical care outreach service. There are also supplementary results not included in the main data, which are referenced in the main body of the text.

\section{Supplementary Files}

This is a list of supplementary files associated with this preprint. Click to download.

- AdditionalFile1.docx

- AdditionalFile2.docx 